\title{
Evidence that the endosomal sorting complex required for transport-II (ESCRT-II) is required for efficient human immunodeficiency virus-1 (HIV-1) production
}

\author{
Bo Meng ${ }^{1}$, Natasha CY Ip ${ }^{1}$, Liam J Prestwood ${ }^{1}$, Truus E M Abbink ${ }^{1,2}$ and Andrew M L Lever ${ }^{1 *}$
}

\begin{abstract}
Background: Egress of a number of different virus species from infected cells depends on proteins of the endosomal sorting complexes required for transport (ESCRT) pathway. HIV has also hijacked this system to bud viruses outward from the cell surface. How ESCRT-I activates ESCRT-III in this process remains unclear with conflicting published evidence for the requirement of ESCRT-II which fulfils this role in other systems. We investigated the role of ESCRT-II using knockdown mediated by siRNA and shRNA, mutants which prevent ESCRT-I/ESCRT-II interaction and a CRISPR/Cas9 EAP45 knockout cell line.

Results: Depletion or elimination of ESCRT-II components from an HIV infected cell produces two distinct effects. The overall production of HIV-1 Gag is reduced leading to a diminished amount of intracellular virion protein. In addition depletion of ESCRT-II produces an effect similar to that seen when ESCRT-I and -III components are depleted, that of a delayed Gag p26 to p24 +p2 cleavage associated with a reduction in export of virion particles and a visible reduction in budding efficiency in virus producing cells. Mutants that interfere with ESCRT-I interacting with ESCRT-II similarly reduce virus export. The export defect is independent of the decrease in overall Gag production. Using a mutant virus which cannot use the ALIX mediated export pathway exacerbates the decrease in virus export seen when ESCRT-II is depleted. ESCRT-II knockdown does not lead to complete elimination of virus release suggesting that the late domain role of ESCRT-II is required for optimal efficiency of viral budding but that there are additional pathways that the virus can employ to facilitate this.
\end{abstract}

Conclusion: ESCRT-II contributes to efficient HIV virion production and export by more than one pathway; both by a transcriptional or post transcriptional mechanism and also by facilitating efficient virus export from the cell through interactions with other ESCRT components.

Keywords: HIV, ESCRT, Late domain, Virus budding

\section{Background}

Budding of human immunodeficiency virus-1 (HIV1) from an infected cell is known to be mediated by the endosomal sorting complexes required for transport (ESCRT) machinery recruited by either TSG101/Vps23 (human protein and yeast homologue, respectively) of

\footnotetext{
*Correspondence: amll1@medschl.cam.ac.uk

1 Department of Medicine, University of Cambridge, Addenbrooke's

Hospital, Cambridge, UK

Full list of author information is available at the end of the article
}

ESCRT-I and/or ALIX, both via the p6 domain of Gag, the major structural protein of the core of HIV [1]. The amino acid motifs in $\mathrm{p} 6$ critical for these two pathways are PTAP and YPXnL (where X refers any amino acid and $\mathrm{n}=1-3$ residues; abbreviated to YPXL hereafter), respectively. Both pathways require the downstream ESCRT-III and VPS4 ATPase. ALIX is able to recruit CHMP4 of ESCRT-III directly, however its contribution to HIV-1 budding appears to be minimal in certain cell lines unless it is overexpressed [2-4]. For the pathway 
mediated by TSG101, the link between ESCRT-I and -III is unclear. In yeast, ESCRT-I, -II and -III act consecutively in the formation of multivesicular bodies and ESCRT-II is crucial for the activation of ESCRT-III [5].

ESCRT-II is a Y-shaped complex comprised of two EAP20/Vps25 subunits, each forming one arm, and one copy each of EAP30/Vps22 and EAP45/Vps36 which together form the third arm [6-8]. ESCRT-II binds to ubiquitinated cargos and to membranes [7, 9, 10]. Together with ESCRT-I, it deforms membranes and induces bud formation in vitro [11]. Both copies of the ESCRT-II subunit EAP20/Vps25 are required to induce conformational changes and to activate ESCRT-III CHMP6/Vps20 for membrane scission $[8,12,13]$.

In the context of HIV-1 budding, previous reports showed that siRNA mediated depletion of the ESCRT-II subunit EAP20 did not appear to affect virus or virus-like particle (VLP) release $[14,15]$ and it was concluded that the infectivity of viruses was unaffected up to $48 \mathrm{~h}$ after knockdown [14]. Effects at later time points were not investigated in detail although knockdown of CHMP6 reduced infectious $\mathrm{HIV}-1$ production four to five fold at $48 \mathrm{~h}$; this however was ascribed to a general effect on protein trafficking. More recently, using a giant unilamellar vesicular system and full length myristylated HIV-1 Gag, it was shown that whereas ALIX can directly recruit the key ESCRT-III subunit CHMP4, ESCRT-I can only recruit CHMP4 when ESCRT-II and CHMP6 are present as intermediary factors [16]. ESCRT-II was also believed to be dispensable for normal cytokinesis [17] but a more recent report shows that EAP20/Vps25 is required for the recruitment of CHMP6 for ESCRT-mediated abscission [18].

Following an initial observation that ESCRT-II knockdown appeared to inhibit HIV-1 production we analysed its role in viral replication using a range of assays including: knockdown with interfering RNA, dominant negative protein expression and the use of an EAP45 knockout cell line. We present evidence consistent with ESCRT-II having at least two roles in efficient HIV-1 production, one of which is enhancement of viral budding.

\section{Results}

Knockdown of ESCRT-II with shRNA reduces the production of infectious virus

To minimise confounding off-target effects from individual short hairpin RNAs (shRNA) and to serve as independent controls for the same target, up to three shRNA expression plasmids were constructed targeting the individual subunits of ESCRT-II (Table 1). They were transiently transfected into cells. We confirmed by Western blot at $96 \mathrm{~h}$ post transfection that cell viability was not affected by the knockdowns (Fig. 1a) and that the
Table 1 Sequences targeted by the shRNA expression plasmids used

\begin{tabular}{ll}
\hline shRNA & Target sequence \\
\hline shControl & TGGTTTACATGTCGACTAA \\
shEAP20-1 & CGTCAAGCTACAGCGAAAG \\
shEAP20-2 & CCTCGAGTGGTTGGATAAG \\
shEAP30-6 & GGAACTACATCAACAGGTG \\
shEAP30-7 & CCAGGATGTCAGTCAAGAT \\
shEAP30-8 & ACCTGATCAGAGCCATCAA \\
shEAP45-1 & GAATAAGGGCTGTAGGAAT \\
shEAP45-2 & TGATCAAGGCTAAGGAAT
\end{tabular}

The target sequence for shControl was derived from Dharmacon ON-TARGETplus siRNA. The remaining were selected using Clontech RNAi Target Sequence Selector (http://bioinfo.clontech.com/rnaidesigner/sirnaSequenceDesignlnit.do) and MWG Biotech websites (http://www.eurofinsdna.com/products-services/ sirna/sirna-design.html).

targeted subunits of ESCRT-II were effectively depleted (Fig. 1b, c, d). In agreement with previous publications, we also noted that the expression of ESCRT-II proteins was mutually dependent; knockdown of one ESCRT-II subunit led to a reduction of all three (data not shown) $[19,20]$. We validated the shRNA system for the study of virus replication using DDX3 as a positive control (Additional file 1: Figure S1) [21]. To assess ESCRT-II in the context of a single cycle of virus replication we cotransfected into cells a combination of plasmids capable of producing vesicular stomatitis virus-glycoprotein (VSVG)-pseudotyped HIV-1 together with shRNA expression vectors targeting one each of the ESCRT-II components. We measured production of HIV Gag p24 capsid (CA) protein and its release using a CA-p24 ELISA. The infectivity of the pseudotyped particles generated from cells was analysed by TZMbl infectivity assay. By $48 \mathrm{~h}$ there was evidence of inhibition of both $\mathrm{p} 24$ production and virion infectivity (Additional file 2: Figure S2). Following a media change at $72 \mathrm{~h}$ this was more readily seen at $96 \mathrm{~h}$ by which time all the shRNAs that had effectively knocked down their targets also caused significant inhibition of viral replication (Fig. 1e, $f, g$ ).

To ensure that this was not an artefact of the VSVpseudotype system the experiment was repeated using wild type HIV. Virus production was again analysed $96 \mathrm{~h}$ post-transfection and similar results were obtained (Fig. 1h, i, j). Knock down of individual ESCRT-II components thus impairs HIV-1 protein production. There is a decrease in intracellular p24 protein detected but, most markedly by $96 \mathrm{~h}$, we also noted a relatively greater decline in supernatant p 24 and viral infectivity compared to the fall in intracellular p24 suggestive of an additional budding defective phenotype. 
a

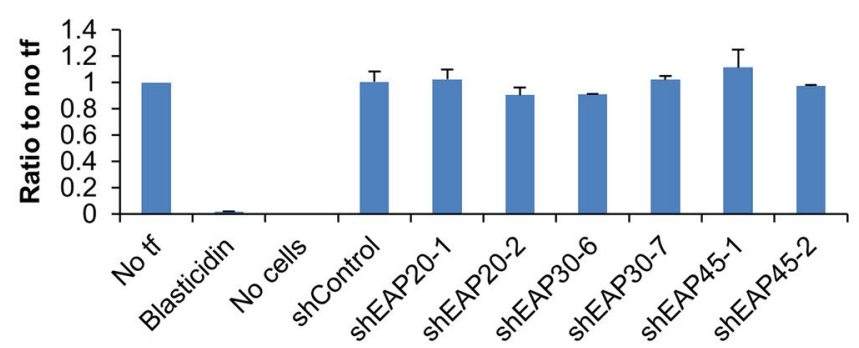

b

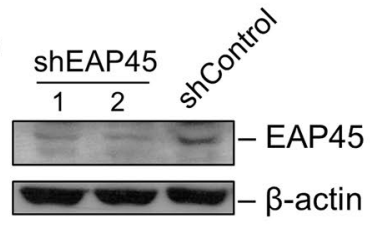

e

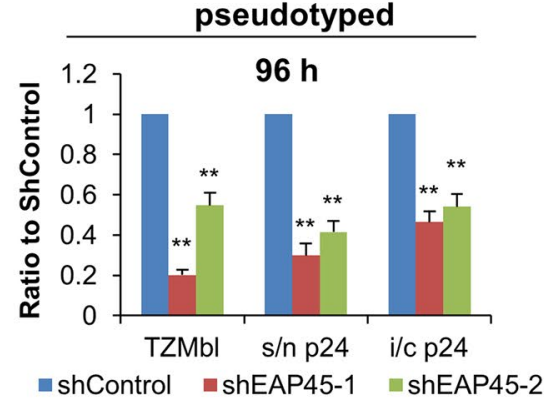

f

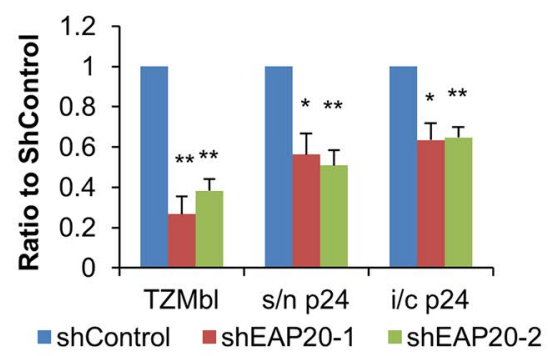

g

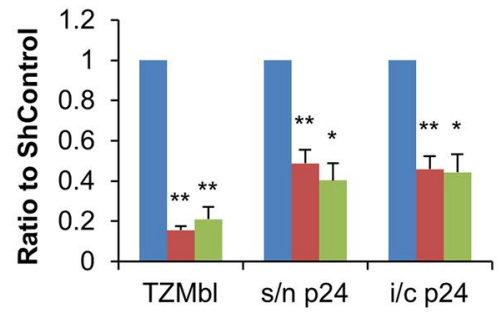

c

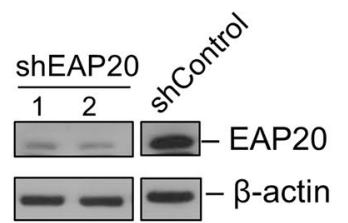

d

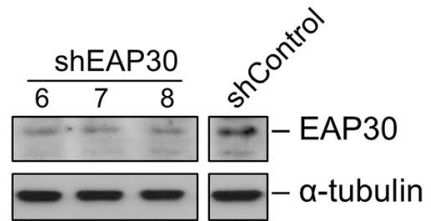

h

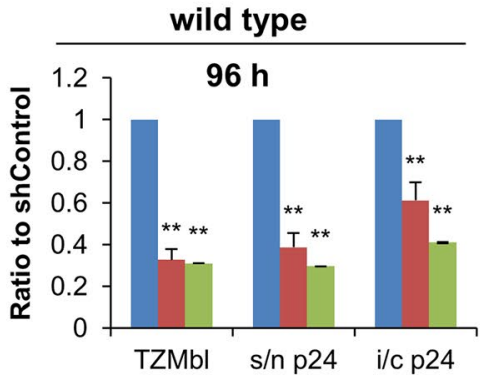

i
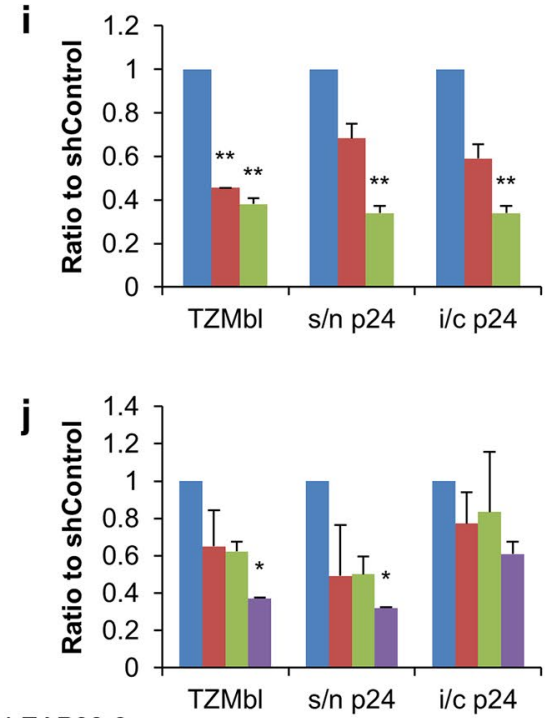

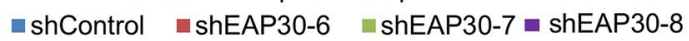

Fig. 1 Inhibition of infectious virus production by knockdown of ESCRT-II. a Cell viability upon knockdown of ESCRT-II subunits was determined using CellTiter-Glo Luminescent Cell Viability Assay (Promega, $n=2$ ) and normalised to that of the non-transfected control (no-tf). Cells treated with blasticidin served as a control for the viability assay. b-d Knockdown of ESCRT-II subunits in HeLaM cells. Cells were transfected with 50 ng shRNA expression plasmids using Fugene HD (Roche). Cells were harvested $96 \mathrm{~h}$ post-transfection and the levels of EAP20, EAP30 and EAP45 were analysed by Western blots. Detection of $\beta$-actin and $\alpha$-tubulin showed equal loading. $\mathbf{e}-\mathbf{j}$ Production of infectious pseudotyped (e-g) and wild type viruses $(\mathbf{h}-\mathbf{j})$ upon knockdown of ESCRT-II subunits: EAP45 $(\mathbf{e}, \mathbf{h})$, EAP20 (f, i i) and EAP30 (g, j). The levels of supernatant (s/n p24) and intracellular (i/c p24) CA-p24 were quantified using ELISA. Virus infectivity was determined by infecting TZMbl cells with equal volumes of supernatant from the virus-producing HeLaM cells. Pseudotyped virus $(\mathbf{e}-\mathbf{g})$ was harvested at $96 \mathrm{~h}$ post-transfection $(n \geq 3)$. Wild type virus $(\mathbf{h}-\mathbf{j})$ was harvested at $96 \mathrm{~h}$ post-transfection $(n \geq 2)$. All bars represent the standard error of the mean (SEM); $n=$ number of independent experiments. Unpaired, two-tailed Student's $t$ test with unequal variance was performed. In all figures ${ }^{*} p<0.05 ;{ }^{* *} p<0.01 ;{ }^{* * *} p<0.001$. 


\section{Disrupting ESCRT I/ESCRT-II interaction inhibits production of infectious virus}

The EAP45 component of human ESCRT-II contains a GLUE (GRAM-like ubiquitin-binding in EAP45) domain followed by the linker HO helix, a helical domain (HD) and two winged helix (WH) domains (Fig. 2a) [7]. EAP45 binds to ubiquitin via its GLUE domain [22]. Together with EAP30, the EAP45 GLUE domain also targets ESCRT-II to endosomal and non-endosomal membranes. Moreover, the H0 helix plays an important role for ESCRT-II binding to VPS28 of ESCRT-I. A four amino acid mutation in $\mathrm{HO}(\mathrm{HOm})$ substantially reduced the interaction in vitro [7]. An isolated GLUE domain was also not sufficient to interact with ESCRT-I [7].

We used two mutants (an isolated GLUE domain and the EAP45 mutant IERK159-162AAAA, designated H0m below) to seek evidence of a direct interaction occurring between ESCRT-I and ESCRT-II in HIV particle budding. As determined by Western blot, transfection of GLUE alone led to overexpression (Fig. 2b). H0m transfected and untransfected cells showed no difference in EAP45 expression levels due to interdependency of the ESCRT-II subunits (data not shown). The untagged HOm could not be distinguished from wild type EAP45 on Western blot due to the few amino acid changes, but an $\mathrm{HA}$-tagged variant verified that the mutations in $\mathrm{HOm}$ did not prevent its expression (Fig. 2c). The transfection of either mutant did not affect cell survival (Fig. 2d).

Viral plasmids were co-expressed with either wild type EAP45 or one of the two mutant EAP45 proteins. Compared to cells transfected with the control firefly luciferase, wild type EAP45 had no effect on the production of infectious wild type virus (Fig. 2e). By contrast, overexpression of GLUE or expression of HOm, significantly and reproducibly resulted in a decline in intracellular p24 but a proportionally larger fall in extracellular p24 and virion infectivity at $96 \mathrm{~h}$ post-transfection (Fig. 2e). Since the GLUE domain is the cargo-binding domain of ESCRTII and both GLUE and HOm interact less efficiently with ESCRT-I than with EAP45 [7], their expression in HIV1-producing cells likely diverted cargos that are relevant to viral particle production from the ESCRT machinery. Thus a direct interaction between ESCRT-I and ESCRTII would appear to facilitate the normal production of infectious HIV-1.

\section{Knockdown of either TSG101 or EAP20 produces a similar phenotype}

We further investigated the involvement of ESCRT-II in HIV budding using siRNA targeted against EAP20 and compared it to disrupting ESCRT-I. As expected knockdown of TSG101 led to a late domain defective phenotype with reduced virus export and impaired terminal cleavage of p24/p2 to p24 (Fig. 3a). This was shown by Western blot and confirmed by image analysis (data not shown) and ELISA (Fig. 3b, c) and the measurements converted into a 'release ratio'. Strikingly the same phenotype of Gag processing and virus release was evident in the EAP20 knockdown cells, again supporting a role for ESCRT-II in HIV budding from the cell in concert with ESCRT-I.

\section{Knockdown of ESCRT-II has an additive effect on release of YPXL mutant virus}

If inhibiting viral export by reducing ESCRT-II is occurring through interference with the PTAP pathway, as occurs with TSG101 knockdown, then blocking the alternative ALIX pathway should produce an additive effect when ESCRT-II is depleted. To investigate this possibility we used a Gag protein mutated in the YPXL motif [27]. This mutation of YPXL does not affect viral gene expression (Additional file 3: Figure S3A). We observed a reduction in virus release upon EAP20 knock down similar to that seen when TSG101 is depleted (Additional file 3: Figure $\mathrm{S} 3 \mathrm{~B}, \mathrm{C})$. We followed the effects on the release ratio in 'real time' by performing pulse chase experiments. The YPXL mutation shows reduced virion export which is further exacerbated when either TSG101 or EAP20 is depleted by siRNA reduction, compared to WT (Fig. 4), consistent with the previous observations. The degree of perturbation detected is modest but this likely relates to the relatively fast kinetics of virion assembly relative to the time points of the chase.

\section{Virus production is affected in CRISPR/Cas 9 EAP45 knockout cells}

Interfering RNA experiments have potential drawbacks in that there may be incomplete knockdown of the target protein and that only very low levels of the factor targeted may be sufficient to carry out the process being probed. We sought to eliminate these concerns using a CRISPR/Cas 9 knock out EAP45 HAP1 cell line constructed by targeting exon 3 of the EAP45 gene (NM_016075). Sanger sequencing confirmed the $20 \mathrm{nt}$ deletion within exon 3 (Additional file 4: Figure S4A). Parental and EAP45 knockout (KO) HAP1 cells were seeded in a 24 well plate and cells were transfected with pseudotyped HIV. The transfection efficiency is comparable as evidenced by the similar level of GFP expressing cells (Additional file 4: Figure S4B). The viability of KO cells is similar with that of parental cells suggesting that absence of EAP45 does not cause deleterious effects on cell proliferation (Additional file 4: Figure S4C). $48 \mathrm{~h}$ post transfection, cells were lysed and supernatant harvested for virion purification. Western blot demonstrates a decrease in $\mathrm{p} 24$ associated viral products from 
a

EAP45 wt

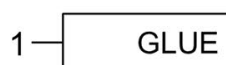

\begin{tabular}{|l|l|l|}
\hline $\mathrm{H} 0$ & $\mathrm{HD}$ & $\mathrm{WH} 1$ \\
\hline
\end{tabular}

WH2 $-386$

GLUE

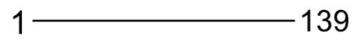

$\mathrm{HOm}$

IERK159-162AAAA 386

b
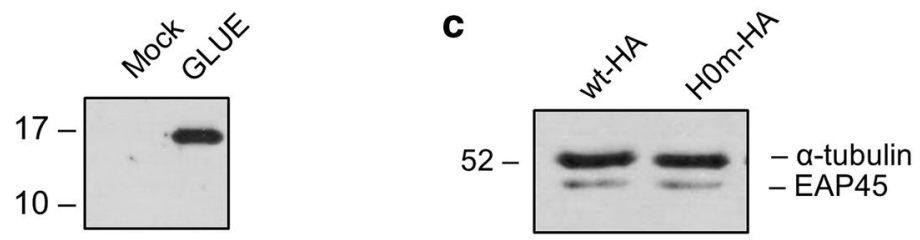

d

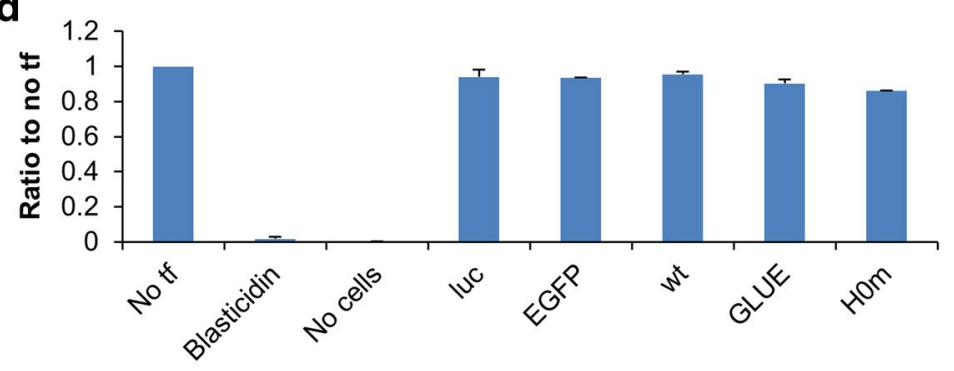

e

wild type

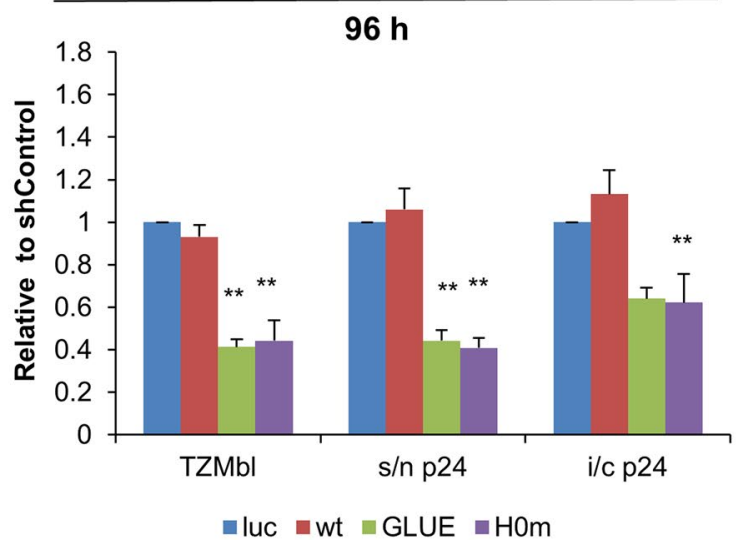

Fig. 2 Reduction in infectious virus production by EAP45 mutants. a Domain organisation of EAP45 and mutants used in this study. b Western blot detecting the expression of GLUE as a $16 \mathrm{kDa}$ protein by a polyclonal rabbit anti-EAP45 antibody. c HA-tagged wt or HOM EAP45 expression plasmids were transfected into the cells. The level of expression was visualised by Western blot using anti-HA antibody. Tubulin is served as a loading control. d Cell viability assay performed as described for Fig. 1a. e Productions of infectious wild type viruses upon co-transfection of EAP45 mutants harvested $96 \mathrm{~h}$ post-transfection are shown. Transfections and analyses were performed as in Fig. 1. Error bars representing the SEM from up to six replicates are shown.

the EAP45 knockout cell line compared to the parental cell control (Fig. 5). This result is consistent with the shRNA knockdown experiment where a reduction in intracellular p24 was also observed (Fig. 1). To further investigate at what stage this occurs, the HAP1 cells were infected with equivalent amounts of pseudotyped
HIV-1 vector and the amount of HIV specific RNA transcripts was measured $24 \mathrm{~h}$ post infection by visualisation under fluorescence microscopy using Quasar ${ }^{\circledR} 570$ Dye labelled multiple oligonucleotide probes (Fig. 6a). The fluorescence intensity at $300 \mathrm{~ms}$ exposure time was measured. The level of HIV RNA is noticeably decreased 


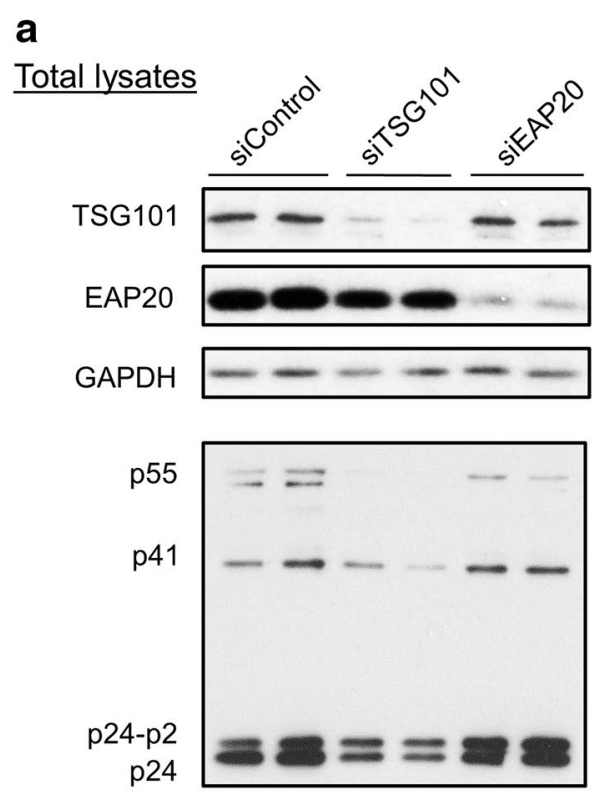

\section{$\underline{\text { Virions }}$}
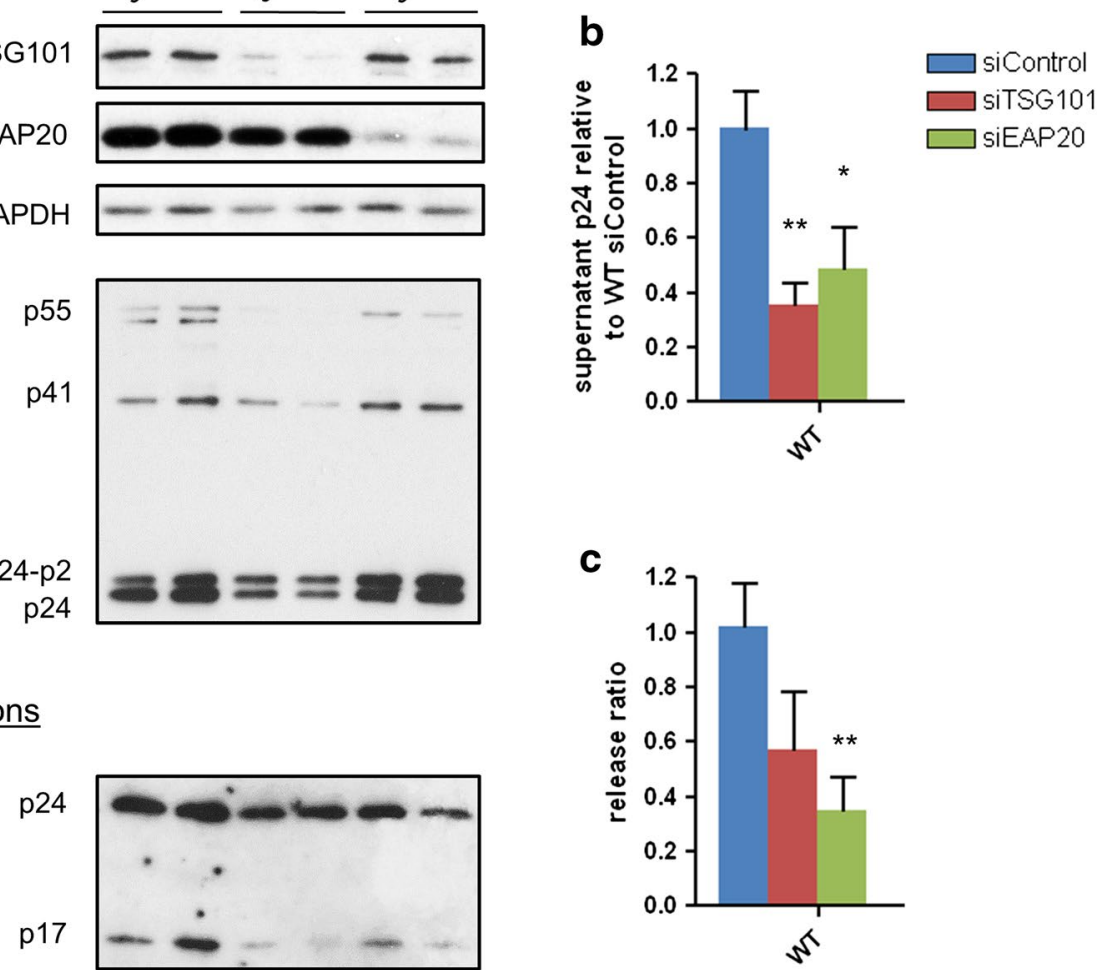

Fig. 3 EAP20 is involved in virus release. a 293T cells were transfected with siControl, siTSG101 or siEAP20. Plasmids generating HIV pseudotyped with VSV-G were co-transfected with the second dose of siRNA post $24 \mathrm{~h}$ transfection. $48 \mathrm{~h}$ post second transfection total cell lysates were harvested and the supernatant was cushion-purified followed by Western blot analyses. b The supernatant extracellular p24 from WT transfected cells under each condition was normalised to that of siControl. c Extracellular p24 is divided by intracellular p24 to give the release ratio before being normalised to siControl. Error bars represent the SEM from six replicates. Statistical analyses were done using two-tailed Student $t$ test with the statistical significance shown by asterisks.

in the HAP1 knockout cell line in comparison with that of the control cell line (Fig. 6b). This would be consistent with a defect in transcription caused by EAP45 knockout. A decline in Gag protein causing a reduced stability of genomic RNA would be unlikely to account for the reduced detection of RNA seen as much of the signal is nuclear and Gag/genomic RNA interactions in HIV are not thought to occur within the nucleus.

A role for EAP45 solely at a transcriptional or early post transcriptional stage would not explain the disproportionate decrease in virion release from ESCRT-II knocked down cells compared to the intracellular levels of viral p24 protein (Fig. 1). In addition the rate of Gag processing appeared to be impaired in the EAP45 knockout cells, especially the terminal cleavage of $\mathrm{p} 24 / \mathrm{p} 2$ to p24 compared to the parental cells (Fig. 5).

To explore this further we compared virus export in the HAP1 EAP45 knockout and HAP1 wild type cells.
Identical numbers of each cell type were transfected with pseudotyped HIV expressing either wild type Gag or PTAP mutated Gag. $48 \mathrm{~h}$ after transfection, the supernatant was collected and virions purified by ultracentrifugation; cells were lysed for Western blot analysis. As expected, the PTAP mutant produced less virions from both cell types (Fig. 7a). However in addition we noted a disproportionate decrease in virus export from the EAP45 knockout cells (Fig. 7b). Quantitation of the release ratio after normalisation to the total p24-associated viral products shows that there is a significant reduction in virion release from EAP45 knockout cells (Fig. 7c). This suggests that while ESCRT-II is not absolutely required for budding its presence promotes efficient virion release. Knock out of EAP45 produces a defect in the final cleavage of p24 from p24-p2 (Fig. 7d) substantiating the involvement of ESCRT-II at the final stage of virus budding. 


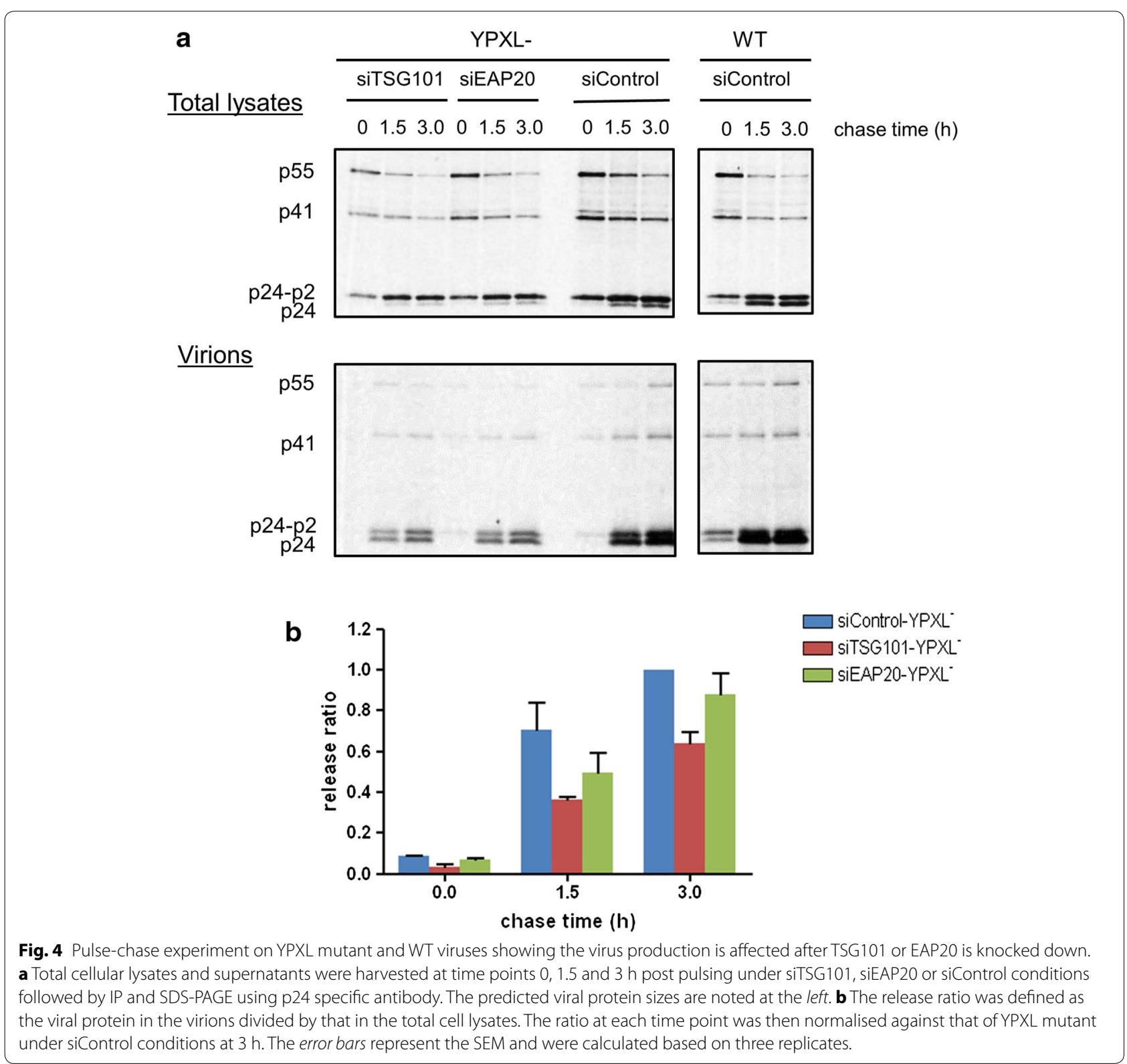

Defects in late domain pathways typically manifest as a failure to complete the viral budding process with significant numbers of virions arrested at an early stage of export at the plasma membrane. We examined viral budding by transmission electron microscopy in the parental and EAP45 knockout cell lines (Fig. 8). While virions can be seen budding normally from the wild type cells with free virus in the intercellular spaces, in the EAP45 knockout cells there are multiple incompletely budded virions detectable at the plasma membrane. This phenotype is very similar to that seen in other late domain defects [23-27] and provides strong evidence for the involvement of ESCRT-II in the budding process.

\section{Discussion}

The ESCRT machinery was originally discovered in yeast where it was found to be essential for the sorting of cargos into intraluminal vesicles for degradation. Studies in yeast and in vitro reconstitution experiments showed that ESCRT-0, I, -II, -III and the Vps4-Vta1 complexes are sequentially involved in this pathway (reviewed in [28]). ESCRT-II proteins are crucial for this; overexpression of ESCRT-II rescues yeast ESCRT-I deletion mutants but not vice versa [29].

Humans possess a conserved homologous pathway and the role of ESCRT in HIV-1 budding is well established [1] with recent evidence suggesting a scaffolding 


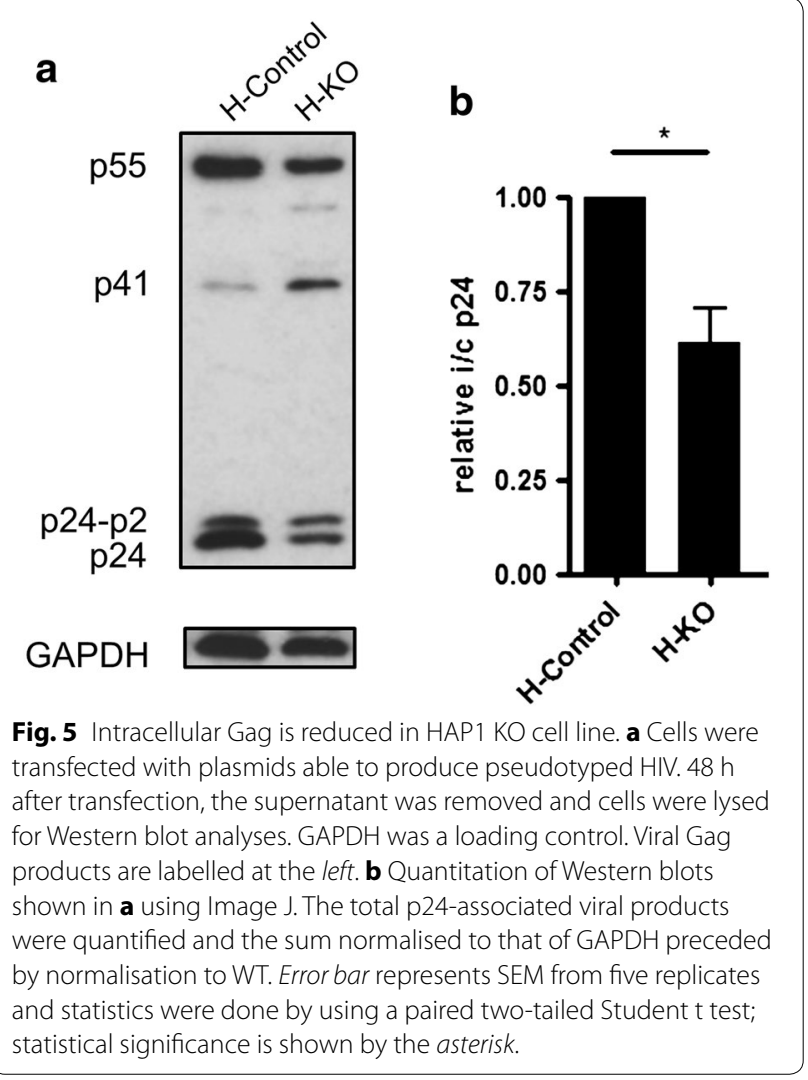

interaction between the viral Gag protein and ESCRT components at the site of virus assembly [30]. The involvement of ESCRT-II has been the subject of debate for HIV and certain other systems. Specific cellular cargos including ferroportin [31] and CXCR4 [19] require ESCRT-II for their lysosomal degradation following internalisation, while others (Kaposi sarcoma-associated herpesvirus ubiquitinated MHC-I) do not [20]. For epidermal growth factor receptor (EGFR), one of the most widely studied ESCRT cargos, the data are conflicting $[14,19,20]$.

Budding and release of HIV-1 is a topologically similar process to endosomal vesicle formation in which the membrane also evaginates from the cytoplasm. ESCRTI, -III and the ESCRT-associated protein ALIX have been firmly implicated in the process. The p6 region of Gag contains two late domains, the PTAP and YPXL motifs that bind TSG101 and ALIX, respectively (reviewed in $[32,33])$. Both of the TSG101 and ALIX pathways require the recruitment of certain ESCRT-III subunits and VPS4 ATPase [34, 35]. ALIX is able to recruit ESCRT-III directly [36], however in certain cell lines its contribution to HIV-1 budding is a minor one unless it is overexpressed $[4,37]$. For the predominant pathway mediated by TSG101, the link between ESCRT-I and -III is still unclear. Langelier et al. concluded that HIV-1 release was ESCRT-II-independent since the depletion of the ESCRT-II subunit EAP20 by small interfering RNA did not appear to cause a significant effect on viral release and infectivity as measured up to $48 \mathrm{~h}$ post transfection in a pseudotyped viral system. A similar phenotype was noted using wild type virus harvested at $24 \mathrm{~h}$ post transfection. They did however report that, at delayed time points, knockdown of ESCRT-II had a deleterious effect on virus production [14]. Pincetic et al. showed that the fusion of EAP20 or EAP45 to the C-terminal of HIV-1 Gag containing a PTAP motif mutation did not rescue budding of virus-like particles whereas it did rescue ASLV [15]; their work also highlighted the different cell membranes involved in budding used by HIV and ASLV. It is unknown however whether the fused EAP20 and EAP45 used in their studies were properly folded and fully functional. Two copies of EAP20 are required to activate ESCRT-III $[8,12,13]$ and isolated EAP45 is unstable without the other ESCRT-II partners due to its extensive exposed hydrophobic regions $[7,8,19,20]$. How ESCRT-III is activated without ESCRT-II was unexplained [28]. Recently however a reconstituted assembly model of HIV using myristylated Gag and giant unilamellar vesicles, presented evidence that ESCRT-II was necessary for the TSG101-mediated pathway to function for viral particle assembly [16].

We have now used several established and novel approaches to study this controversial area including two different knockdown protocols with two different viral strains in different cell lines and also a CRISPR/Cas 9 EAP45 knockout cell line. In both HeLaM and 293T cell lines a defect was observed in viral export when ESCRTII was knocked down. Importantly in no case was there a detectable decrease in cell viability at the late time points assayed, indicating that our findings were specific and did not reflect a generalised effect on vesicular sorting in the cell (Figs. 1a, 2d, Additional file 4: Figure S4C). EAP20 plays an important role in recruiting CHMP6 for correct cytokinesis [18] and the expression of ESCRT-II components is mutually dependent [19, 20 and this study]. However, the depletion of EAP45 does not noticeably affect cell proliferation suggesting the level of EAP20 is sufficient for normal cell division.

In HeLaM cells the effect of EAP45 knockdown on viral budding was masked to some extent by a decline in Gag production as measured by intracellular p24 (Fig. 1) but this decrease can now be explained as ESCRT-II appears to have an additional earlier effect on HIV protein production (Figs. 5, 6). Both knockdown and knockout experiments document a decline in intracellular Gag production indicating that there may be a transcriptional or post transcriptional effect of ESCRT-II. The magnitude of 

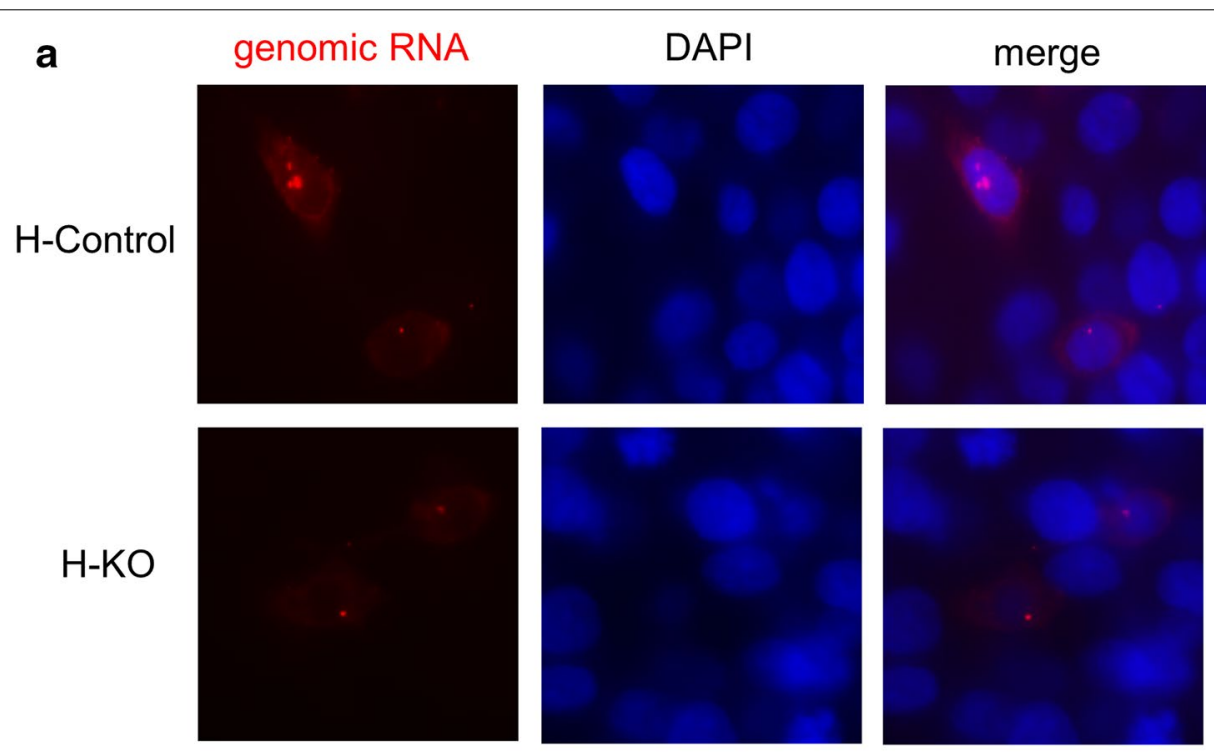

b

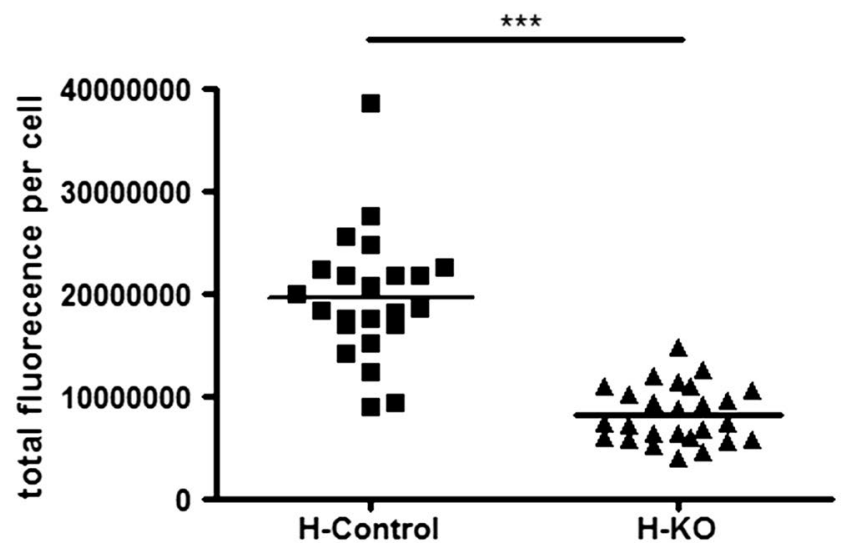

Fig. 6 RNA FISH analyses of HIV infected HAP1 cells. a The same number of either HAP1 control cells or HAP1 knockout cells was infected with pseudotyped HIV. $24 \mathrm{~h}$ after infection, the supernatant was removed and the cells subjected to RNA FISH analysis by fluorescence microscopy. b The area of each individual genomic RNA positive control or knockout cell was defined and the fluorescence intensity was quantitated using image J. A total number of 23 or 26 cells, respectively, was identified from either control cells or knockout cells in two experiments. The statistics were done using unpaired two-tailed Student t test with the statistical significance shown by asterisks.

this effect seems to be cell type dependent. In $293 \mathrm{~T}$ cells, the total p24-associated viral products are relatively unaffected (data not shown) consistent with a previous report [14]. However, in HelaM and HAP1 cells a more significant decrease in p24-associated viral products is seen (Figs. 1, 5). ESCRT-II has been shown to have transcriptional effects in other systems [38] but this has not been investigated in detail in the context of HIV. Despite the reduction in Gag production partially obscuring the later budding effect to some degree the latter is strikingly clear in the EAP45 knockout cell line (Figs. 7, 8) suggesting that ESCRT-II although not indispensable for production of infectious virus, contributes significantly to efficient particle release.
Viruses released from the PTAP mutated provirus transfected cells may be using the intact YPXL-ALIX pathway. Interestingly the fold reduction in release ratio between WT and PTAP mutant from the control cell line is similar to that from the knockout cells suggesting the proportion of viruses using YPXL-ALIX pathway is unaltered. The additive defect in infectious virus production observed after TSG101 or EAP20 are knocked down in the context of a co-transfected YPXL mutant virus, suggests that both TSG101 and EAP20 are indeed involved in the budding process (Additional file 3: Figure S3, Additional file 4: Figure S4). The time course release ratio from pulse-chase experiments corroborates this (Fig. 4). The effect seen is less dramatic but pulse chase conditions 


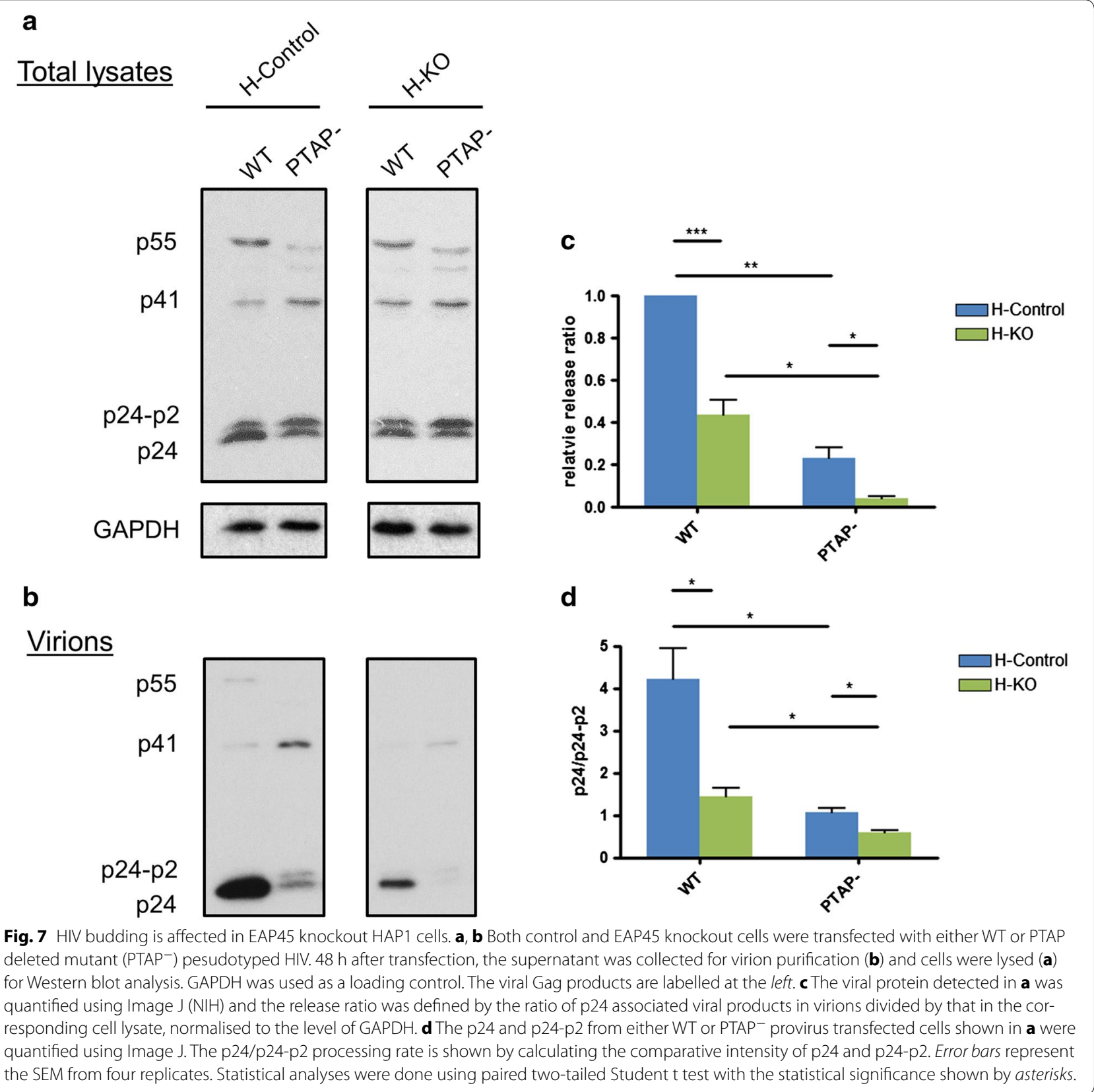

may be suboptimally sensitive to detection of alterations in viral assembly, which is very rapid $[39,40]$.

One of the hallmarks of the defect caused by inhibiting the ESCRT pathway is a generalised delayed rate of Gag processing which is especially marked at the final stage of cleavage of p24 from p24-p2 [2, 14, 27, 41]. We consistently see the same defect in EAP20 depleted cells (Fig. 3, Additional file 3: Figure S3) and EAP45 knock out cells (Figs. 5,7 ). Similar effects in Gag processing occur in the side by side TSG101 and EAP20 knockdown conditions. The exaggerated effect of a PTAP mutant transfected into the EAP45 knock out cell line (Fig. 7d) implies that ESCRT-I and ESCRT-II may play similar or complementary roles at the early stage of virus budding. Although not cell lines for which HIV is tropic, all of these monolayer cells allow a precise assessment of a single step viral life cycle and facilitate standardisation of the infectivity assay. In addition suspension cells such as lymphocytes are less easily synchronised and cell division might be affected by ESCRT-II knockdown, which would likely impinge directly on HIV replication. The findings from gene depletion experiments (Figs. 1, 3, 4, 5, 7) together 

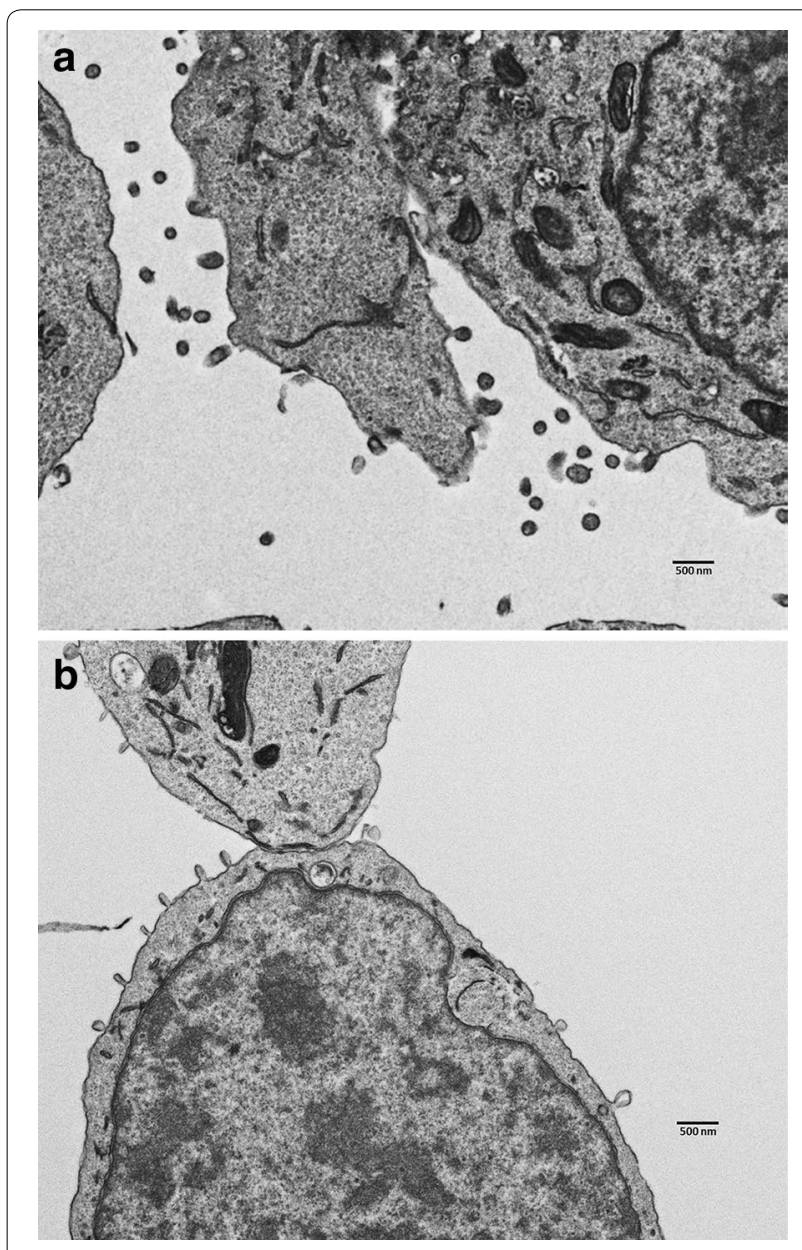

Fig. 8 Transmission electron microscopy of thin-sectioned parental (a) and EAP45 knockout cells (b) transfected with pseudotyped HIV. Note the free virions surrounding the active budding sites in $\mathbf{a}$ and tethered budding particles on the plasma membrane in $\mathbf{b}$. Bar equals $500 \mathrm{~nm}$.

with a consistency of effect using a dominant negative interference approach (Fig. 2) strongly suggest that ESCRT-II contributes to efficient virus budding and production of infectious HIV-1 and that the effect of ESCRTII is mediated through its interaction with ESCRT-I.

It has been suggested that the self-assembly of Gag is sufficient to deform the membrane into a bud making a role for ESCRT-II dispensable. However three dimensional analysis of the viral budding site argues that ESCRT contributes to membrane deformation during the early stage of Gag assembly and that membrane scission is not the only role of ESCRT [26]. ESCRT-II participates in membrane deformation as shown by an in vitro reconstitution assay [11] and by modelling of the crystal structure of ESCRT-II-CHMP6 $6_{2}$ with membranes [12]. Our EM data confirm that in the absence of ESCRT-II components budding is slowed or arrested and help to resolve some of the controversy surrounding HIV virus release.

\section{Conclusion}

The ESCRT system of proteins is involved in more than one process of viral production in HIV-1. ESCRT-II contributes to efficient transcriptional and/or post-transcriptional generation of HIV Gag. Additionally, there is clear evidence that the presence of ESCRT-II makes a significant contribution to the budding and viral export process of the virus and that this involves a co-ordinated link with ESCRT-I.

\section{Methods \\ Cells}

HeLaM, a derivative of HeLa cells [42] and 293T cell lines were obtained from ATCC. TZMbl, carrying two HIV-1 LTR-driven reporter genes, firefly luciferase and $E$. coli $\beta$-galactosidase $[43,44]$, is a HeLa cell clone that stably expresses high levels of CD4 and CCR5 and was obtained from NIH AIDS Research and Reference Reagent Program. The HAP1 EAP45 CRISPR/Cas 9 knockout and control cell lines were constructed and purchased from Haplogen $\mathrm{GmbH}$, Vienna, Austria. They were grown in Iscove's modified Dulbecco's medium (IMDM) supplemented with $10 \%$ fetal calf serum (FCS). HeLaM, 293T and TZMbl cells were grown in Dulbecco's modified Eagle medium (DMEM) supplemented 10\% FCS. All cell lines were grown at $37^{\circ} \mathrm{C}$ and $5 \% \mathrm{CO}_{2}$ incubator.

\section{Plasmids}

pSVC21 $\triangle$ BglII is derived from a pHXB2 infectious clone but with a BglII fragment in the env gene (7041$7621)$ deleted $[45,46]$. The BH10 strain was a kind gift of Michael Laughrea, McGill University, Canada. The analogous BglII deletion provirus was created in BH10. YPXL and PTAP deletion mutants of pBH10 $\Delta$ BglII were constructed using site directed mutagenesis [27, 47]. pCMVVSV-G encodes the VSV glycoprotein for pseudotyping. pLAI is a full-length molecular clone of HIV-1 strain LAI for the expression of wild type virus [48]. pTER vector [49] was obtained from van der Wetering (Centre for Biomedical Genetics, The Netherlands) and was used for cloning shRNA into BamHI and XhoI sites to generate individual pTER-shRNA. pGEX4T1-EAP20, pGEX4T1EAP30, pGEX4T1-EAP45 [20] and pEGFPC2-HSV1TK were obtained for the cloning of genes of interest to $\mathrm{pEF}$ vector containing human elongation factor $1 \alpha$ according to Lee et al. [50]. Mutagenesis PCR was used to introduce the IERK 159-162 AAAA mutation in the H0 helix of EAP45 [7]. 


\section{Cell viability}

The manufacturer's protocol for CellTiter-Glo Luminescent Cell Viability Assay (Promega) was adapted for 96-well half-area plates. Briefly, the cell culture plate was equilibrated at room temperature for $30 \mathrm{~min}$. CellTiterGlo Reagent $(50 \mu \mathrm{l})$ was added to each well and the plate was placed on an orbital shaker (750 rpm, Titramax 100, Heidolph) for $2 \mathrm{~min}$ to lyse cells. After a further 10-min incubation at room temperature, luminescence was read with a $1 \mathrm{~s}$ integration time using GloMax 96 Microplate Luminometer (Promega).

\section{Pseudotyped and wild type virus production with shRNA or EAP45 expression}

To produce pseudotyped virus, HeLaM cells of $50-80 \%$ confluency were co-transfected in a 24-well plate format with $44 \mathrm{ng}$ pSVC21 $\triangle \mathrm{BglII}$ and $15.6 \mathrm{ng}$ pCMV-VSV-G in an optimised ratio of 3.7:1.3 using Fugene HD (Roche). A total amount of $200 \mathrm{ng}$ pBH10 $\Delta$ BglII and pCMV-VSV-G was co-transfected into $50-80 \%$ HAP1 cells in a $24-$ well plate using TurboFectin 8.0 (Origene). For wild type virus, cells were transfected with $40 \mathrm{ng}$ pLAI. Transient expression of shRNA was performed by co-transfecting pTER-shRNA with the viral plasmids. For pseudotyped virus, $120 \mathrm{ng}$ shRNA expression plasmid together with the above mentioned quantities of DNA plasmids for pseudotyping were transfected. For wild type virus, $50 \mathrm{ng}$ shRNA expression plasmid and $40 \mathrm{ng}$ LAI were co-transfected. In the EAP45 mutant experiments HeLaM were transiently co-transfected with $200 \mathrm{ng}$ EAP45 mutant expression plasmids. $200 \mathrm{ng}$ EAP45 mutant expression plasmids was also used for the wild type virus study. In all the above experiments, viruses were harvested at 48 or $96 \mathrm{~h}$ post-transfection and the supernatant was used to infect TZMbl cells to assay for infectivity. The medium was replaced $24 \mathrm{~h}$ prior to harvesting at $96 \mathrm{~h}$ to study the released viruses at late point. Supernatant was inactivated in Empigen (0.1\%; Sigma-Aldrich) in PBS. Virusproducing cells were lysed in $150 \mu \mathrm{l} /$ well of $1 \%$ Empigen in Passive Lysis Buffer (Promega). Extracellular and intracellular CA-p24 levels were quantified by ELISA (Aalto) with a slight modification [51].

\section{Virus infectivity}

Infectivity was based on the Tat-dependent upregulation of LTR-driven firefly luciferase expression upon HIV-1 infection of TZMbl cells. Cells $\left(\sim 10^{5}\right)$ were seeded in 24-well plates in $0.5 \mathrm{ml} /$ well of complete DMEM. Equal volumes of medium from virus-producing cells were added to TZMbl cells. DEAE-dextran $(50 \mu \mathrm{g} / \mathrm{ml}$; AppliChem) was added to facilitate infection. TZMbl cells were lysed at $48 \mathrm{~h}$ post-infection in $150 \mu \mathrm{l} /$ well of Cell
Culture Lysis Reagent (CCLR; Promega). Firefly luciferase expression was quantified using the Luciferase Assay System (Promega). Cell lysates $(5 \mu \mathrm{l})$ were transferred to a white 96-well half-area plate. Luciferase Assay Reagent $(25 \mu \mathrm{l})$ was added and the luminescence was measured by GloMax 96 Microplate Luminometer (Promega).

\section{RNA FISH}

Around $1 \times 10^{5}$ either HAP1 control or EAP45 KO cells were seeded in each well of an 8 well multi-well glass slide (Millipore). After $24 \mathrm{~h}$, the cells were infected with HIV-VSV-G containing $200 \mathrm{ng}$ supernatant p24. After $24 \mathrm{~h}$ infection, the media was removed and washed once with PBS before fixing with formaldehyde in PBS (3.7\%) for $10 \mathrm{~min}$ at room temperature. This was followed by washing with PBS and permeabilising with $70 \%$ ethanol at $4^{\circ} \mathrm{C}$ for $1 \mathrm{~h}$. The probe set composing 37 oligonucleotides labelled with Quasar ${ }^{\circledR} 570$ Dye at the $5^{\prime}$ end was purchased from Biosearch Technologies specifically targeting HIV Gag coding region. The hybridisation process was followed according to manufacturer's instructions. The vectashield was applied before the coverslip was mounted and visualised under Olympus Ix81 fluorescence microscope. The TRITC channel was used for genomic RNA visualisation. The images were taken by pre-setting at $300 \mathrm{~ms}$ exposure time. For fluorescence quantitation, the genomic RNA positive cells were identified and the area of each individual cell was defined and quantified using ImageJ (NIH).

\section{siRNA knockdown}

The Stealth siRNA (Life technologies) knockdown was performed using TransIT-TKO transfection reagent (Mirus) based on the manufacturer's instructions. Briefly, one well of $50 \%$ confluent $293 \mathrm{~T}$ cells in a 24 well plate was transfected with $2 \mu \mathrm{l}, 20 \mu \mathrm{M}$ Stealth siRNA to EAP20, TSG101 or control using $2.5 \mu \mathrm{l}$ TransIT-TKO. Total amount of $40 \mathrm{ng} \mathrm{pBH} 10 \Delta \mathrm{BglII}$ and pCMV-VSV-G was mixed with $160 \mathrm{ng}$ pBluescript empty vector and followed by co-transfection with second dose of $2 \mu \mathrm{l}, 20 \mu \mathrm{M}$ siRNA $24 \mathrm{~h}$ post first dose transfection. The supernatant was collected $72 \mathrm{~h}$ post first dose transfection and clarified by low centrifugation before ELISA for p24 quantitation or Optiprep cushion ultracentrifugation for virion purification for Western analysis. Total cells were lysed with $150 \mu \mathrm{l} 1 \times$ CCLR before being subjected to ELISA and Western blot analysis using mouse monoclonal antibodies to TSG101 (Abcam) and to HIV-1 p55/ p24 (ARP313, NIBSC) and rabbit polyclonal antibodies to GAPDH (Abcam) and EAP20 (P Luzio, Cambridge Institute for Medical Research, UK). Quantification of Western blots was performed using ImageJ (NIH). For 
knockdown conditions for the pulse-chase experiments one well of fifty percent confluent $293 \mathrm{~T}$ cells in a 6 well plate was transfected with $8 \mu \mathrm{l}, 20 \mu \mathrm{M}$ Stealth siRNA to EAP20, TSG101 or control using $10 \mu \mathrm{l}$ TransIT-TKO. A total of $2 \mu \mathrm{g}$ pBH10 10 BglII and $135 \mathrm{ng}$ pCMV-VSV-G was co-transfected with second dose of Stealth siRNA as above. After $48 \mathrm{~h}$ post first transfection, the cells were labelled with ${ }^{35} \mathrm{~S}$ protein labeling mix (Perkin-Elmer) as described in the pulse-chase method section.

\section{Pulse-chase analysis}

Pulse-chase analysis was performed by adapting the method of L'Hernault et al. [52]. Briefly, 293T cells were transfected with $2 \mu \mathrm{g}$ pBH10 $\triangle$ BglII and $135 \mathrm{ng}$ pCMVVSV-G in 6-well plates. After $24 \mathrm{~h}$, cells were washed and starved in $0.5 \mathrm{ml}$ of DMEM lacking methionine and cysteine (Met-Cys-free DMEM; Sigma-Aldrich) supplemented with $4 \mathrm{mM}$ glutamine and $10 \%$ FCS. Cells were then pulse-labelled for $30 \mathrm{~min}$ with $0.5 \mathrm{ml}$ of Met-Cysfree DMEM supplemented with $110 \mu \mathrm{Ci}$ of EasyTag Express ${ }^{35} \mathrm{~S}$ protein labeling mix $(11 \mathrm{mCi} / \mathrm{ml}$; PerkinElmer). The medium was removed and supplemented with fresh complete DMEM with $2 \mathrm{mM}$ Met and $2 \mathrm{mM}$ Cys when time point zero was set. Cells were chased at 90 and 180 min post labelling. At each time point the viruscontaining supernatants were harvested and clarified by low speed centrifugation. Cells were lysed with RIPA buffer (50 mM Tris- $\mathrm{HCl}$ [pH 7.5], $100 \mathrm{mM} \mathrm{NaCl}, 1 \%$ sodium deoxycholate, $0.1 \%$ SDS, $1 \%$ Triton X-100, protease inhibitor cocktail [Roche]). The capsid and Gag proteins were immunoprecipitated using $3.25 \mu \mathrm{g}$ anti-HIV-1 p55/p24 mouse monoclonal antibody (ARP313, NIBSC) at $4^{\circ} \mathrm{C}$. Protein G-Sepharose beads (Sigma-Aldrich) were then added to the mixtures for a further $1 \mathrm{~h}$ rotation before being spun and washed in RIPA buffer. Finally, the beads were resuspended in $50 \mu \mathrm{l} 2 \times$ Laemmli buffer. Samples were boiled for $5 \mathrm{~min}$ before being loaded onto a 15\% SDS-polyacrylamide gel. Gels were fixed and dried prior to autoradiography. Quantification was performed using Image $(\mathrm{NIH})$.

\section{Electron microscopy of budding virus}

The HAP1 control cells and KO cells were transfected as described above. $48 \mathrm{~h}$ post transfection, the supernatant was removed and the monolayer of cells was washed with $9 \% \mathrm{NaCl}$ followed by fixation in $2 \%$ glutaraldehyde and $2 \%$ formaldehyde in $0.05 \mathrm{M}$ cacodylate buffer overnight. The cells were scraped and collected by centrifugation before being embedded and thin-sectioned. The thin-sectioned samples were mounted on an EM grid and visualised using a Tecnai G2 electron microscope. Images were taken at 3,500 $\times$ magnification.

\section{Additional files}

Additional file 1: Figure S1. Validation of shRNA system for the study of HIV-1 replication. (A) Western blot detecting the knockdown of DDX3 by shDDX3 (target sequence CATTGAGCTTACTCGTTAT) in HeLaM cells. (B) Cell viability assay performed as described for Figure 1A. (C-D) Production of infectious pseudotyped ( $c$, mean $\pm S E M, n=4$ ) and wild type (d, mean \pm SD of duplicate samples) viruses upon knockdown of DDX3, $96 \mathrm{~h}$ post-transfection. Transfections and analyses were performed as described for Figure 1.

Additional file 2: Figure S2. Inhibition of pseudotyped virus production by knockdown of ESCRT-II. As for Figure 1 (A: EAP45; B: EAP20; C: EAP30) showing results at $48 \mathrm{~h}$ post transfection.

Additional file 3: Figure S3. Budding effects from $\mathrm{YPXL}^{-}$transfected cells upon knocking down TSG101 or EAP20. (A) as described in Figure 3A except YPXL mutant provirus was used in the transfection. (B) The supernatant extracellular p24 from $\mathrm{YPXL}^{-}$transfected cells under each condition was normalised against to that of WT siControl from Figure 3. (D) Extracellular p24 is divided by intracellular p24 to give the release ratio before being normalised to WT siControl from Figure 3. Error bars represent the SEM from six replicates.

Additional file 4: Figure S4. Characterisation of CRISPR/Cas9 EAP45 knockout HAP1 cell line. (A). Sanger sequencing confirms that there is a 20 nt deletion (underlined) in exon 3 of HAP1 EAP45 knockout cell line. (B). The transfection efficiency of both control and knockout cell lines were monitored by transfecting a eGFP expression construct. (C). Cell viability assay of WT provirus transfected HAP1 and KO cells. Non-transfected and blasticidin treated cells served as controls. The error bars represent the SEM from two replicates.

\section{Authors' contributions}

BM participated in the design of the study, drafting of the manuscript and carried out molecular and cell biological assays including interfering RNA, cell knockout and EM studies. NI participated in the design of the study and carried out interfering RNA and dominant negative studies and contributed to drafting the manuscript. LP contributed to the viral assays and helped draft the manuscript. TA participated in the design and coordination of the studies and the drafting of the manuscript. AL conceived of the study, participated in its design and coordination and helped write the manuscript. All authors read and approved the final manuscript.

\section{Author details}

${ }^{1}$ Department of Medicine, University of Cambridge, Addenbrooke's Hospital, Cambridge, UK. ${ }^{2}$ Present Address: Centre for Childhood White Matter Disorders, VU University Medical Centre, Amsterdam, The Netherlands.

\section{Acknowledgements}

We thank Roger Williams (MRC Laboratory of Molecular Biology, Cambridge, UK) for many helpful discussions. We thank Jeremy Skepper in the Multiimaging Centre for help with the electron microscopy. We thank Paul Luzio (Cambridge Institute for Medical Research, Cambridge, UK) for the kind gift of EAP20 antibody, Herald Stenmark (University of Oslo, Norway) for providing the antibodies against EAP30 and EAP45, Laurence Tiley (University of Cambridge, UK) for pCMV-VSV-G, Michael Laughrea for providing the BH10 infectious clone (McGill University, Canada) and Marc van de Wetering (Centre for Biomedical Genetics, The Netherlands) for the plasmid vector for shRNA expression. The work was supported by the Cambridge Biomedical Research Centre.

\section{Compliance with ethical guidelines}

\section{Competing interests}

The authors declare that they have no competing interests.

Received: 11 June 2015 Accepted: 31 July 2015

Published online: 14 August 2015 


\section{References}

1. Meng B, Lever AM (2013) Wrapping up the bad news: HIV assembly and release. Retrovirology 10:5

2. Fisher RD, Chung HY, Zhai Q, Robinson H, Sundquist Wl, Hill CP (2007) Structural and biochemical studies of ALIX/AIP1 and its role in retrovirus budding. Cell 128(5):841-852

3. Martin-Serrano J, Bieniasz PD (2003) A bipartite late-budding domain in human immunodeficiency virus type 1. J Virol 77(22):12373-12377

4. Fujii K, Munshi UM, Ablan SD, Demirov DG, Soheilian F, Nagashima K et al (2009) Functional role of Alix in HIV-1 replication. Virology 391(2):284-292

5. Babst M, Odorizzi G, Estepa EJ, Emr SD (2000) Mammalian tumor susceptibility gene 101 (TSG101) and the yeast homologue, Vps23p, both function in late endosomal trafficking. Traffic 1(3):248-258

6. Hierro A, Sun J, Rusnak AS, Kim J, Prag G, Emr SD et al (2004) Structure of the ESCRT-II endosomal trafficking complex. Nature 431(7005):221-225

7. Im YJ, Hurley JH (2008) Integrated structural model and membrane targeting mechanism of the human ESCRT-II complex. Dev Cell 14(6):902-913

8. Teo H, Perisic O, Gonzalez B, Williams RL (2004) ESCRT-II, an endosomeassociated complex required for protein sorting: crystal structure and interactions with ESCRT-III and membranes. Dev Cell 7(4):559-569

9. Gill DJ, Teo H, Sun J, Perisic O, Veprintsev DB, Emr SD et al (2007) Structural insight into the ESCRT-I/-II link and its role in MVB trafficking. EMBO J 26(2):600-612

10. Teo H, Gill DJ, Sun J, Perisic O, Veprintsev DB, Vallis Y et al (2006) ESCRT-I core and ESCRT-II GLUE domain structures reveal role for GLUE in linking to ESCRT-I and membranes. Cell 125(1):99-111

11. Wollert T, Hurley JH (2010) Molecular mechanism of multivesicular body biogenesis by ESCRT complexes. Nature 464(7290):864-869

12. Im YJ, Wollert T, Boura E, Hurley JH (2009) Structure and function of the ESCRT-II-III interface in multivesicular body biogenesis. Dev Cell 17(2):234-243

13. Teis D, Saksena S, Judson BL, Emr SD (2010) ESCRT-II coordinates the assembly of ESCRT-III filaments for cargo sorting and multivesicular body vesicle formation. EMBO J 29(5):871-883

14. Langelier C, von Schwedler UK, Fisher RD, De Domenico I, White PL, Hill CP et al (2006) Human ESCRT-II complex and its role in human immunodeficiency virus type 1 release. J Virol 80(19):9465-9480

15. Pincetic A, Medina G, Carter C, Leis J (2008) Avian sarcoma virus and human immunodeficiency virus, type 1 use different subsets of ESCRT proteins to facilitate the budding process. J Biol Chem 283(44):29822-29830

16. Carlson LA, Hurley JH (2012) In vitro reconstitution of the ordered assembly of the endosomal sorting complex required for transport at membrane-bound HIV-1 Gag clusters. Proc Natl Acad Sci USA 109(42):16928-16933

17. Carlton JG, Martin-Serrano J (2007) Parallels between cytokinesis and retroviral budding: a role for the ESCRT machinery. Science 316(5833):1908-1912

18. Goliand I, Nachmias D, Gershony O, Elia N (2014) Inhibition of ESCRT-IICHMP6 interactions impedes cytokinetic abscission and leads to cell death. Mol Biol Cell 25(23):3740-3748

19. Malerod L, Stuffers S, Brech A, Stenmark H (2007) Vps22/EAP30 in ESCRT-II mediates endosomal sorting of growth factor and chemokine receptors destined for lysosomal degradation. Traffic 8(11):1617-1629

20. Bowers K, Piper SC, Edeling MA, Gray SR, Owen DJ, Lehner PJ et al (2006) Degradation of endocytosed epidermal growth factor and virally ubiquitinated major histocompatibility complex class I is independent of mammalian ESCRTII. J Biol Chem 281(8):5094-5105

21. Yedavalli VS, Neuveut C, Chi YH, Kleiman L, Jeang KT (2004) Requirement of DDX3 DEAD box RNA helicase for HIV-1 Rev-RRE export function. Cell 119(3):381-392

22. Slagsvold T, Aasland R, Hirano S, Bache KG, Raiborg C, Trambaiolo D et al (2005) Eap45 in mammalian ESCRT-II binds ubiquitin via a phosphoinositide-interacting GLUE domain. J Biol Chem 280(20):19600-19606

23. Gottlinger HG, Dorfman T, Sodroski JG, Haseltine WA (1991) Effect of mutations affecting the $\mathrm{p} 6 \mathrm{gag}$ protein on human immunodeficiency virus particle release. Proc Natl Acad Sci USA 88(8):3195-3199

24. von Schwedler UK, Stray KM, Garrus JE, Sundquist WI (2003) Functional surfaces of the human immunodeficiency virus type 1 capsid protein. J Virol 77(9):5439-5450
25. Demirov DG, Ono A, Orenstein JM, Freed EO (2002) Overexpression of the N-terminal domain of TSG101 inhibits HIV-1 budding by blocking late domain function. Proc Natl Acad Sci USA 99(2):955-960

26. Carlson LA, Briggs JA, Glass B, Riches JD, Simon MN, Johnson MC et al (2008) Three-dimensional analysis of budding sites and released virus suggests a revised model for HIV-1 morphogenesis. Cell Host Microbe 4(6):592-599

27. Dussupt V, Javid MP, Abou-Jaoude G, Jadwin JA, de La Cruz J, Nagashima Ket al (2009) The nucleocapsid region of HIV-1 Gag cooperates with the PTAP and LYPXnL late domains to recruit the cellular machinery necessary for viral budding. PLoS Pathog 5(3):e1000339

28. Hurley JH, Hanson PI (2010) Membrane budding and scission by the ESCRT machinery: it's all in the neck. Nat Rev Mol Cell Biol 11(8):556-566

29. Babst M, Katzmann DJ, Snyder WB, Wendland B, Emr SD (2002) Endosome-associated complex, ESCRT-II, recruits transport machinery for protein sorting at the multivesicular body. Dev Cell 3(2):283-289

30. Van Engelenburg SB, Shtengel G, Sengupta P, Waki K, Jarnik M, Ablan SD et al (2014) Distribution of ESCRT machinery at HIV assembly sites reveals virus scaffolding of ESCRT subunits. Science 343(6171):653-656

31. De Domenico I, Ward DM, Langelier C, Vaughn MB, Nemeth E, Sundquist Wl et al (2007) The molecular mechanism of hepcidin-mediated ferroportin down-regulation. Mol Biol Cell 18(7):2569-2578

32. Freed EO (2003) The HIV-TSG101 interface: recent advances in a budding field. Trends Microbiol 11(2):56-59

33. Fujii K, Hurley JH, Freed EO (2007) Beyond Tsg101: the role of Alix in 'ESCRTing' HIV-1. Nat Rev Microbiol 5(12):912-916

34. Morita E, Sandrin V, McCullough J, Katsuyama A, Baci Hamilton I, Sundquist WI (2011) ESCRT-III protein requirements for HIV-1 budding. Cell Host Microbe 9(3):235-242

35. Jouvenet N, Zhadina M, Bieniasz PD, Simon SM (2011) Dynamics of ESCRT protein recruitment during retroviral assembly. Nat Cell Biol 13(4):394-401

36. McCullough J, Fisher RD, Whitby FG, Sundquist WI, Hill CP (2008) ALIXCHMP4 interactions in the human ESCRT pathway. Proc Natl Acad Sci USA 105(22):7687-7691

37. Strack B, Calistri A, Craig S, Popova E, Gottlinger HG (2003) AIP1/ALIX is a binding partner for HIV-1 p6 and EIAV p9 functioning in virus budding. Cell 114(6):689-699

38. Schmidt AE, Miller T, Schmidt SL, Shiekhattar R, Shilatifard A (1999) Cloning and characterization of the EAP30 subunit of the ELL complex that confers derepression of transcription by RNA polymerase II. J Biol Chem 274(31):21981-21985

39. Jouvenet N, Bieniasz PD, Simon SM (2008) Imaging the biogenesis of individual HIV-1 virions in live cells. Nature 454(7201):236-240

40. Ivanchenko S, Godinez WJ, Lampe M, Krausslich HG, Eils R, Rohr K et al (2009) Dynamics of HIV-1 assembly and release. PLoS Pathog 5(11):e1000652

41. Dussupt V, Sette P, Bello NF, Javid MP, Nagashima K, Bouamr F (2011) Basic residues in the nucleocapsid domain of Gag are critical for late events of HIV-1 budding. J Virol 85(5):2304-2315

42. Tiwari RK, Kusari J, Sen GC (1987) Functional equivalents of interferon-mediated signals needed for induction of an mRNA can be generated by double-stranded RNA and growth factors. EMBO J 6(11):3373-3378

43. Platt EJ, Wehrly K, Kuhmann SE, Chesebro B, Kabat D (1998) Effects of CCR5 and CD4 cell surface concentrations on infections by macrophagetropic isolates of human immunodeficiency virus type 1. J Virol 72(4):2855-2864

44. Wei X, Decker JM, Liu H, Zhang Z, Arani RB, Kilby JM et al (2002) Emergence of resistant human immunodeficiency virus type 1 in patients receiving fusion inhibitor (T-20) monotherapy. Antimicrob Agents Chemother 46(6):1896-1905

45. Fisher AG, Collalti E, Ratner L, Gallo RC, Wong-Staal F (1985) A molecular clone of HTLV-III with biological activity. Nature 316(6025):262-265

46. Richardson JH, Kaye JF, Child LA, Lever AM (1995) Helper virus-free transfer of human immunodeficiency virus type 1 vectors. J Gen Virol 76(Pt 3):691-696

47. Demirov DG, Orenstein JM, Freed EO (2002) The late domain of human immunodeficiency virus type $1 \mathrm{p} 6$ promotes virus release in a cell typedependent manner. J Virol 76(1):105-117 
48. Peden $K$, Emerman M, Montagnier L (1991) Changes in growth properties on passage in tissue culture of viruses derived from infectious molecular clones of HIV-1LAI, HIV-1MAL, and HIV-1ELI. Virology 185(2):661-672

49. van de Wetering $M$, Oving I, Muncan $V$, Pon Fong MT, Brantjes $H$, van Leenen D et al (2003) Specific inhibition of gene expression using a stably integrated, inducible small-interfering-RNA vector. EMBO Rep 4(6):609-615

50. Lee Y, Park EJ, Yu SS, Kim DK, Kim S (2000) Improved expression of vascular endothelial growth factor by naked DNA in mouse skeletal muscles: implication for gene therapy of ischemic diseases. Biochem Biophys Res Commun 272(1):230-235
51. Abbink TE, Berkhout B (2008) RNA structure modulates splicing efficiency at the human immunodeficiency virus type 1 major splice donor. J Virol 82(6):3090-3098

52. L'Hernault A, Weiss EU, Greatorex JS, Lever AM (2012) HIV-2 genome dimerization is required for the correct processing of Gag: a second-site reversion in matrix can restore both processes in dimerization-impaired mutant viruses. J Virol 86(10):5867-5876

\section{Submit your next manuscript to BioMed Central} and take full advantage of:

- Convenient online submission

- Thorough peer review

- No space constraints or color figure charges

- Immediate publication on acceptance

- Inclusion in PubMed, CAS, Scopus and Google Scholar

- Research which is freely available for redistribution

Submit your manuscript at www.biomedcentral.com/submit 